\title{
A simple, azulene-based colorimetric probe for the detection of nitrite in water
}

\author{
Lloyd C. Murfin ${ }^{1}$, Carlos M. López-Alled ${ }^{2}$, Adam C. Sedgwick ${ }^{1}$, Jannis Wenk (凶) $)^{2,3}$, Tony D. James $(\bowtie)^{1,2}$, \\ Simon E. Lewis $(\bowtie)^{1,2}$ \\ 1 Department of Chemistry, University of Bath, Bath BA2 7AY, UK \\ 2 Centre for Sustainable Chemical Technologies, University of Bath, Bath BA2 7AY, UK \\ 3 Department of Chemical Engineering and Water Innovation and Research Centre (WIRC@Bath), University of Bath, Bath BA2 7AY, UK
}

(C) The Author(s) 2019. This article is published with open access at link.springer.com and journal.hep.com.cn

\begin{abstract}
We describe the synthesis and evaluation of an azulene-based chemodosimeter for nitrite. The probe was found to undergo two distinct color changes upon introduction of aqueous nitrite ion. A near-instant formation of a grey color provides a qualitative indication of the presence of nitrite, followed by the formation of a deepyellow/orange color, the endpoint from which quantitative data can be derived. The azulene probe exhibits 1:1 stoichiometry of reaction with nitrite in water, and is selective for nitrite over other anions. The azulene probe was applied to determine nitrite content in cured meat, and compared with the British Standard testing procedure (Griess test). The value obtained from the azulene-based probe agreed closely with the standard test. Our procedure only requires the preparation of one standard solution, instead of the three required for the standard Griess test.
\end{abstract}

Keywords azulene, nitrite, diazoquinone

\section{Introduction}

Nitrite salts such as potassium nitrite $\left(\mathrm{KNO}_{2}, \mathrm{E} 249\right)$ and sodium nitrite $\left(\mathrm{NaNO}_{2}, \mathrm{E} 250\right)$ are commonly used food preservatives. They are employed in the production of "cured" meat products such as dry-cured ham, as part of a salting mixture that typically also contains sodium chloride and nitrate salts such as sodium nitrate $\left(\mathrm{NaNO}_{3}, \mathrm{E} 251\right)$ and potassium nitrate $\left(\mathrm{KNO}_{3}, \mathrm{E} 252\right)$ [1]. The "curing" process gives meat products a longer shelf-life, as the salts cause a barrier effect that retards microbial spoilage due to the

Received September 26, 2018; accepted November 20, 2018

E-mails: J.H.Wenk@bath.ac.uk (Wenk J); T.D.James@bath.ac.uk (James T D); S.E.Lewis@bath.ac.uk (Lewis S E) reduced water activity $\left(a_{\mathrm{W}}\right)$ that results [2]. Furthermore, the nitrite salts affect the color of the meat product and have a positive effect on its organoleptic properties. However, ingested nitrites are classified by the IARC as a group 2A carcinogen, i.e., "probably carcinogenic to humans, under conditions that result in endogenous nitrosation" [3]. This is due to the formation of nitrosating agents from nitrite in the low $\mathrm{pH}$ gastric environment. These in turn may react with amines or amides in vivo, leading to the production of $N$-nitrosamines and $N$-nitrosamides, some of which are known carcinogens. The World Health Organization (WHO) has specified an acceptable daily intake of $0-0.06 \mathrm{mg} / \mathrm{kg}$ of body weight per day for nitrite ion [4]. Nitrite is also a regulated drinking water contaminant with maximum levels of $0.5 \mathrm{mg} / \mathrm{L}$ in the European Union and $1.0 \mathrm{mg} / \mathrm{L}$ in the United States and in WHO guidelines, respectively [5-7].

For the reasons outlined above, it is important to have methods for the quantitation of nitrite content of a given sample. The most commonly used method for determination of nitrite concentration in solution is a test that relies on the Griess reaction [8]. In this process, an aliquot of the sample is added to an acidic solution where protonation of nitrite (1) results in formation of nitrosonium cation 2 $\left(\mathrm{NO}^{+}\right)$. This is then reacted with an appropriate aromatic amine, usually sulfanilamide $\mathbf{3}$, resulting first in the formation of the corresponding $N$-nitrosamine $\mathbf{4}$, and then, after further protonation, the corresponding diazonium salt 5. $N$-(1-Naphthyl)ethylenediamine $\mathbf{6}$ is then added, resulting in the formation of pink azo dye 7 (Scheme 1). Dye 7 has an absorption maximum at $\lambda_{\max }=$ $535 \mathrm{~nm}$, and the absorbance of the solution at this wavelength is measured spectrophotometrically.

In the above test, alternative arylamine and SEAr substrates have been studies in place of $\mathbf{3}$ and 7, but these have been found to be optimal [9]. The selectivity of 


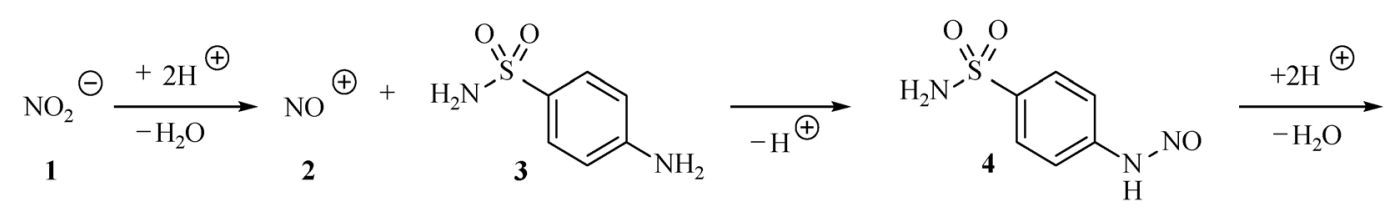

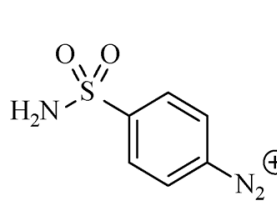

5

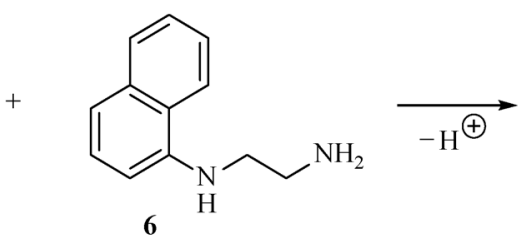

6

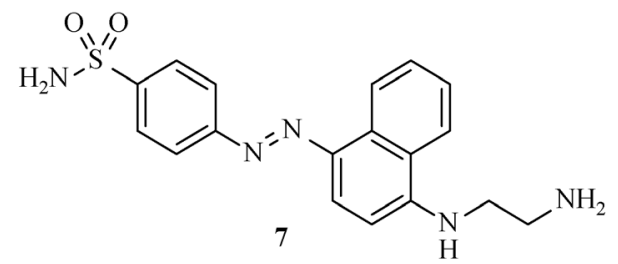

Scheme 1 Mechanism of the Griess test for nitrite

the Griess test for nitrite over other anions derives from the fact that only nitrite is able to diazotize an arylamine under acidic conditions. Thus, other analytes, in particular nitrate ions, give a negative result. This key concept of nitriteinduced diazotization has been exploited in other nitrite probe designs. Gold nanoparticles have been surfacefunctionalized with covalently linked variants of $\mathbf{3}$ and $\mathbf{6}$ - in the absence of nitrite, the colloidal nanoparticles are red due to a surface plasmon resonance, but addition of nitrite results in diazotization and crosslinking of the nanoparticles through the newly formed azo bonds, leading to aggregation and precipitation, and hence loss of color [10]. An alternative approach employing gold nanorods involves surface immobilization of arylamines, which are protonated under the acidic assay conditions, leading to a high positive surface charge. Nitrite induced diazotization followed by reduction (i.e., overall deamination) leads to neutral surface groups, and hence to a decreased surface charge. This in turn leads to aggregation and color change [11]. Further variants employing gold nanostructures have also been described [12-14], as well as a system employing silver nanoparticles [15]. In addition, colorimetric nitrite probes that comprise aryl 1,2-diamine groups have been reported, the diazotization of an amine here leading to the formation of a benzotriazole instead of an azo linkage [16]. In the case of 2-arylethynylaniline colorimetric nitrite probes, diazotization leads to formation of a different heterocycle, $4(1 \mathrm{H})$-cinnolones $[17,18]$. An aza-BODIPY chromophore with conjugated arylamine substituents is reported to show a colorimetric response to nitrite as a result of diazotization [19]. Pyrrole has also been reported to be a colorimetric probe for nitrite, acting by a mechanism other than amine diazotization, although the exact mechanism was not disclosed [20]. Autocatalytic approaches to increase the sensitivity of colorimetric nitrite sensors have been developed [21]. Elsewhere, organometallic complexes have also been reported as colorimetric probes for nitrite $[22,23]$.

The bicyclic aromatic compound azulene 8 (Fig. 1) has an intense blue color, and both it and its derivatives have

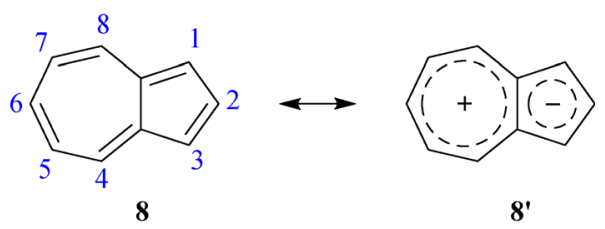

Fig. 1 Structure of azulene

been extensively studied due to their unusual properties. For example, although azulene is isomeric with naphthalene, it possesses a dipole of $1.08 \mathrm{D}$, which is unexpectedly large for a hydrocarbon. In addition, its HOMO to LUMO transition lies in the visible region [24]. One characteristic of azulenes makes them especially suited to applications in colorimetric sensing. The absorption spectrum of azulene is very sensitive to the introduction of substituents onto the azulene ring, allowing access to the full visible spectrum $[25,26]$. Therefore, azulenes have been used in colorimetric probes for a variety of analytes [27-34]. As part of our ongoing work in the areas of azulene chemistry [3537] and chemosensors [38], we wished to develop a probe for nitrite that exploited the diazotization of an azulenylamine to cause a visible color change. Azulenes have been studied in the context of nitrite sensing previously: Sawicki and co-workers reported that the direct combination of azulene 8 and nitrite in acidic medium led to the formation of a species exhibiting an absorption at $\lambda_{\max }=617 \mathrm{~nm}$, although the exact nature of this species was not determined [39]. Garcia employed azulene in a Griess test for nitrite, wherein para-nitroaniline (instead of $\mathbf{3}$ ) was diazotized by nitrite, then reacted with azulene 8 (instead of 6) to form the corresponding azo dye [40]. More recently, a report on a boron-containing azulene derivative describes a spectrophotometric response to nitrite [41], although nitrite sensing was not the focus of this work. Also of note, treatment of azulenes with nitrite salts has been reported to effect aromatic nitration [42,43] (as opposed to nitrosation) in certain specific cases.

Here, we report a selective colorimetric chemodosimeter 


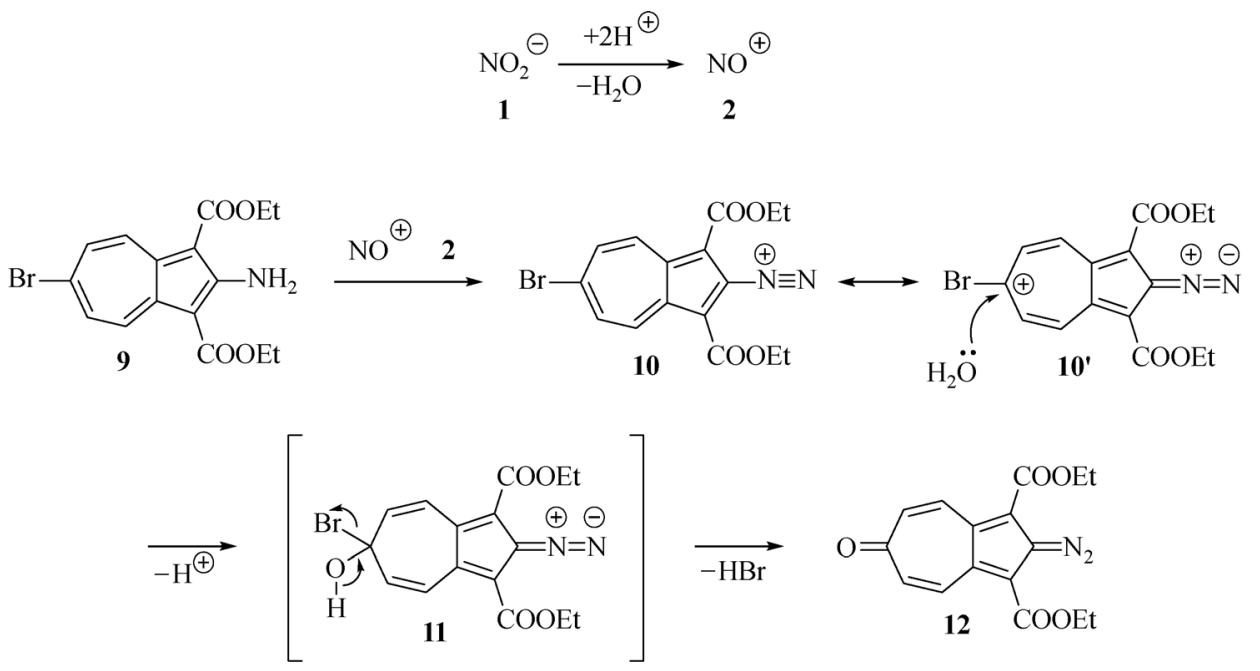

Scheme 2 Reaction of azulene 9 and $\mathrm{NO}_{2}{ }^{-}$

for the detection of nitrite anion that relies on diazotization of an azulenylamine and subsequent formation of a diazoquinone. This is a conceptually distinct approach compared to the more common formation of an azo dye following diazotization; to the best of our knowledge, a colorimetric probe for nitrite with a diazoquinone as the end-point has not previously been reported. Crucially, our approach does not require a coupling reaction to occur between two separate reagents.

\section{Results and discussion}

Our nitrite probe, diethyl 2-amino-6-bromoazulene-1,3dicarboxylate 9, may be synthesized in three steps from tropolone (Scheme S1), and in $71 \%$ overall yield, as previously reported by Nozoe $[44,45]$. Further details are given in the Electronic Supplementary Material (ESM). To evaluate the colorimetric response of $\mathbf{9}$, sodium nitrite was added to a solution of 9 in acetonitrile-water, acidified with $\mathrm{HCl}_{(\mathrm{aq})}$ to $\mathrm{pH} 1$. It is known that choice of solvent can influence both the sensitivity and selectivity of chemical probes [46-48] - in this instance the final solvent ratio $\mathrm{MeCN} / \mathrm{H}_{2} \mathrm{O}$ was $1: 1$. A range of other conditions having different $\mathrm{pH}$ values were also assessed, but it was found that $\mathrm{pH} 1$ was optimum (see ESM for details). A rapid color change was observed, with the solution changing from yellow to grey within $1 \mathrm{~min}$. However, upon further standing of the test solution, a second color change was observed, with the grey color changing to orange after $10 \mathrm{~min}$. These observations may be explained as shown in Scheme 2. Thus, formation of nitrosonium ion 2 from nitrite $\mathbf{1}$ in the acidic medium leads to diazotization of 9 to give azulenyldiazonium species $\mathbf{1 0}$, which we propose is the source of the grey color observed. Whereas in the traditional Griess test the diazonium intermediate reacts with an electron-rich arene to give a diazo product, in this instance (and in the absence of any such aryl nucleophile), 10 can instead react with the solvent. As first proposed by Nozoe [49], the presence of the electron-withdrawing diazonium group at the azulene 2-position renders the azulene 6-position electrophilic. Attack of water at this position, followed by loss of $\mathrm{HBr}$, then affords stable diazoquinone $\mathbf{1 2}$.

In support of the above mechanism, the UV/vis spectrum of the test solution after 10 min was compared to that of an authentic sample of previously synthesised diazoquinone 12, and the two were found to exhibit the same absorption maxima (Fig. 2). Specifically, compared

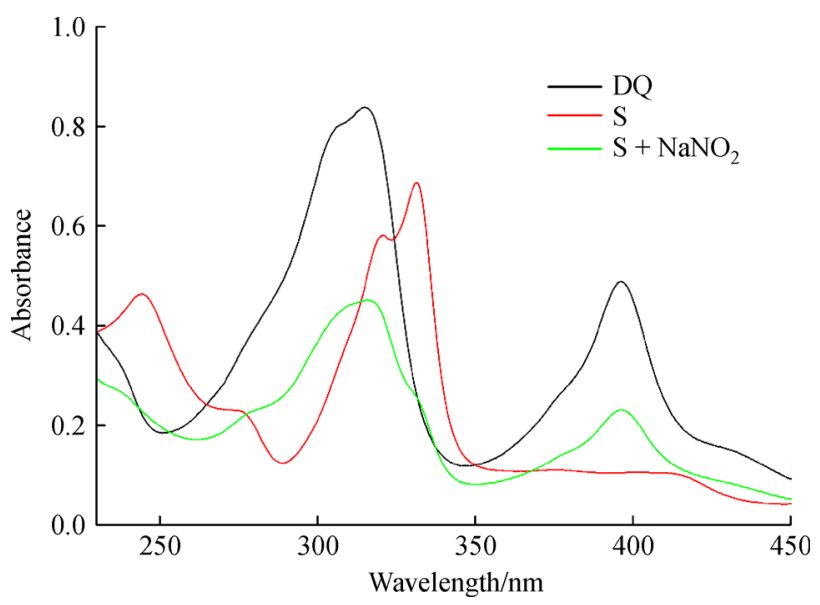

Fig. 2 UV/Vis spectra of azulene $9(\mathrm{~S})$, azulene 9 and $\mathrm{NaNO}_{2}(\mathrm{~S}$ $+\mathrm{NaNO}_{2}$ ), and independently prepared 12 (DQ). Each vial contained the following. For S: MeCN $(4.95 \mathrm{~mL})$, DI water $(2.00 \mathrm{~mL}), \mathrm{HCl}_{(\mathrm{aq})}(35 \%, 3.00 \mathrm{~mL})$, and sensor $9(50 \mu \mathrm{L}, 5 \mathrm{mmol} /$ $\mathrm{L}$ in $\mathrm{MeCN})$. For $\mathrm{S}+\mathrm{NaNO}_{2}: \mathrm{MeCN}(4.95 \mathrm{~mL})$, DI water $(1.95$ $\mathrm{mL}), \mathrm{HCl}_{(\mathrm{aq})}(35 \%, 3.00 \mathrm{~mL}), \mathrm{NaNO}_{2}(50 \mu \mathrm{L}, 5 \mathrm{mmol} / \mathrm{L}$ in DI water), and sensor $9(50 \mu \mathrm{L}, 5 \mathrm{mmol} / \mathrm{L}$ in $\mathrm{MeCN})$. For DQ: MeCN $(4.95 \mathrm{~mL})$, DI water $(2.00 \mathrm{~mL}), \mathrm{HCl}_{(\mathrm{aq})}(35 \%, 3.00 \mathrm{~mL})$, and DQ $12(50 \mu \mathrm{L}, 5 \mathrm{mmol} / \mathrm{L}$ in $\mathrm{MeCN})$ 
to unreacted probe 9 , loss of the absorption maxima at $\lambda=$ $320 \mathrm{~nm}$ and $332 \mathrm{~nm}$ (red line) and the appearance of new absorption maxima at $\lambda=318 \mathrm{~nm}$ and $395 \mathrm{~nm}$ (green line) confirm the formation of $\mathbf{1 2}$.

The dose-response characteristics of chemodosimeter 9 towards nitrite were then assessed (Fig. 3). It was observed that increasing equivalents of nitrite caused an increase in absorbance at $\lambda=318 \mathrm{~nm}$, and a proportional increase in absorbance at $\lambda=395 \mathrm{~nm}$ (of diazoquinone 12), and a decrease in the absorbances at $\lambda=320 \mathrm{~nm}$ and $332 \mathrm{~nm}$ (of probe 9). The intensity of absorbances due to diazoquinone 12 showed no further increase once an excess of nitrite was present in solution (with respect to 9), suggestive of a 1:1 dose-response relationship. The 1:1 stoichiometry was further evidenced with a Job plot and calibration curve, the latter showing that the absorbance at $395 \mathrm{~nm}$ reaches a plateau once one equivalent of nitrite is added (See Fig. S1 and Fig. S2 of ESM).

We next examined the selectivity of probe 9 for nitrite over a variety of other anions. As shown in Figs. 4 and 5, 9 exhibited no response to chloride, bromide, iodide, hydrogen sulfate, bicarbonate and hydrogen phosphate under the same conditions. Most significantly, 9 also showed no response to nitrate; difficulty in discriminating between nitrite and nitrate is known to be a characteristic of certain probe designs [50].

An advantage of nitrite probe 9 is the rapidity of its response to nitrite under the assay conditions, and the speed with which the grey color of $\mathbf{1 0}$ develops. Achieving a color change visible to the naked eye within a minute compares favorably to most protocols based on Griess reactions. As $\mathbf{1 0}$ is not the end-point for this assay, the appearance of the grey color must be interpreted in a qualitative sense only, and quantitation of nitrite should be

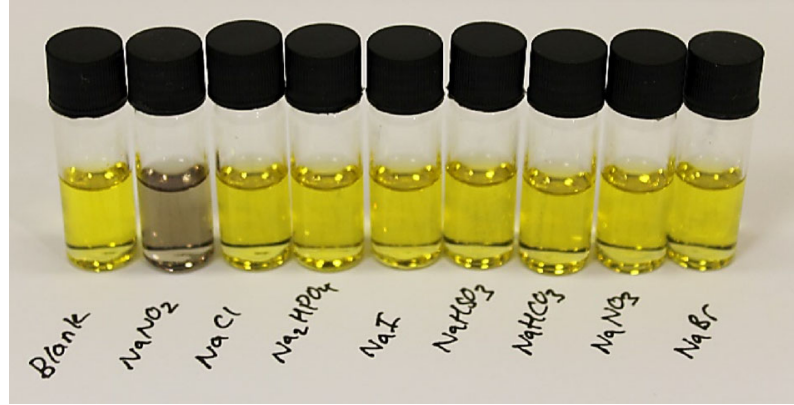

Fig. 4 Selectivity of azulene probe 9 and various anions in solution after $1 \mathrm{~min}$. Each vial contains a mixture of $\mathrm{MeCN}$ $(0.4 \mathrm{~mL})$, DI water $(0.1 \mathrm{~mL}), \mathrm{HCl}_{(\mathrm{aq})} 35 \%(0.3 \mathrm{~mL})$, sensor 9 $(0.1 \mathrm{~mL}, 5 \mathrm{mmol} / \mathrm{L}$ in $\mathrm{MeCN})$ and analyte $(0.1 \mathrm{~mL}, 5 \mathrm{mmol} / \mathrm{L}$ in DI water)

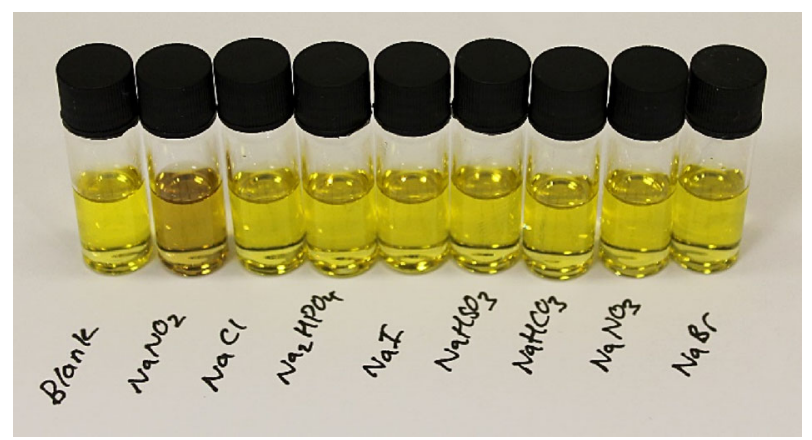

Fig. 5 Selectivity of azulene probe 9 and various anions in solution after $10 \mathrm{~min}$. Each vial contains a mixture of $\mathrm{MeCN}$ $(0.4 \mathrm{~mL}), \mathrm{DI}$ water $(0.1 \mathrm{~mL}), \mathrm{HCl}_{(\mathrm{aq})} 35 \%(0.3 \mathrm{~mL})$, sensor 9 $(0.1 \mathrm{~mL}, 5 \mathrm{mmol} / \mathrm{L}$ in $\mathrm{MeCN})$ and analyte $(0.1 \mathrm{~mL}, 5 \mathrm{mmol} / \mathrm{L}$ in DI water)

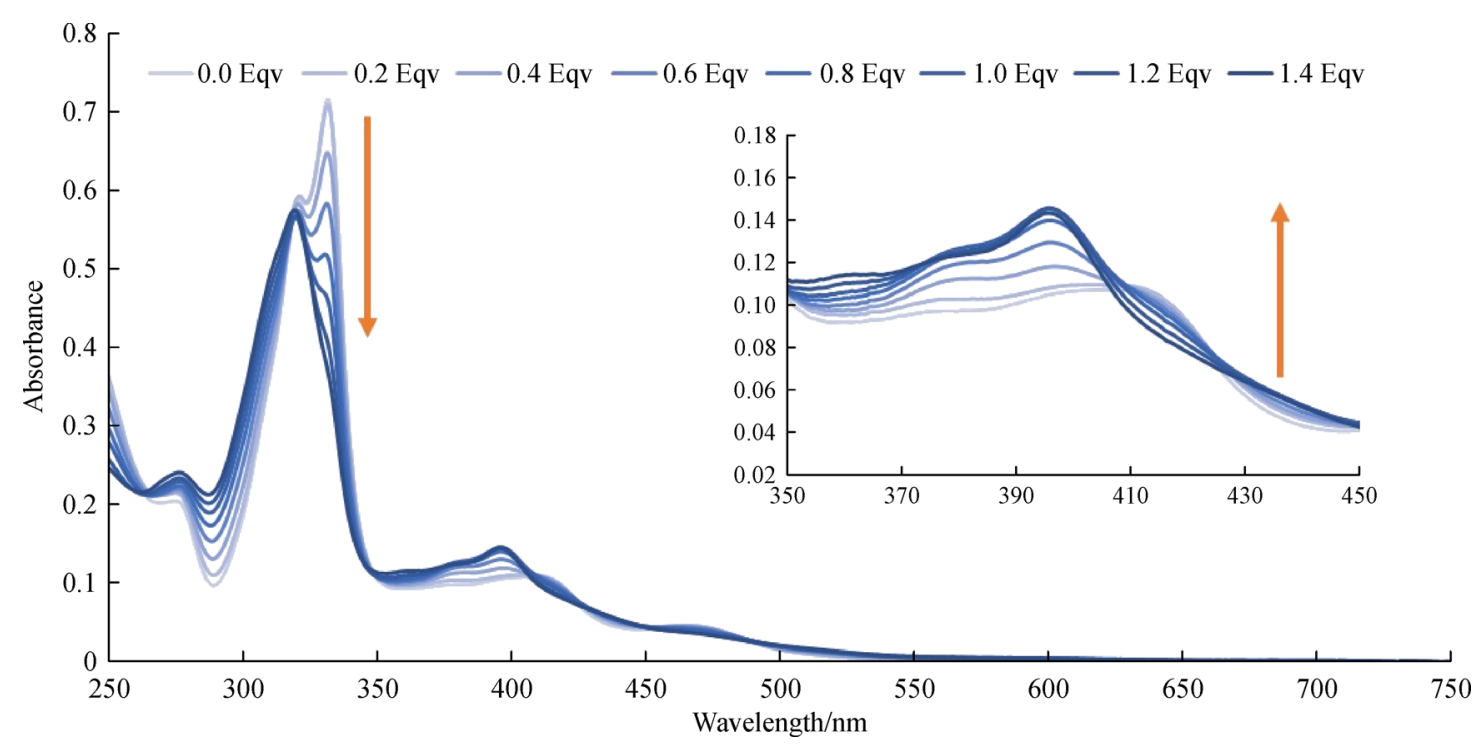

Fig. 3 Dose-response of probe 9 against increasing equivalence of $\mathrm{NaNO}_{2}$. Results taken after 20 min of nitrite addition to allow full conversion to diazoquinone 12. Titration was performed in a mixture of $\mathrm{MeCN}(4.95 \mathrm{~mL})$, DI water $(2.00 \mathrm{~mL})$ and $\mathrm{HCl}_{(\mathrm{aq})}(35 \%, 3.00$ $\mathrm{mL})$, with probe $9(50 \mu \mathrm{L}, 5 \mathrm{mmol} / \mathrm{L}$ in $\mathrm{MeCN})$ and subsequent aliquots of analyte $(10 \mu \mathrm{L}, 5 \mathrm{mmol} / \mathrm{L}$ in DI water) 
based on the absorbances arising from diazoquinone 12, which forms more slowly. Nevertheless, this feature of our probe provides additional information to the experimentalist. Quantitation of the probe's response to the other potentially interfering anions was carried out by measuring the absorbance at the maximum at $395 \mathrm{~nm}$, as shown in Fig. 6.

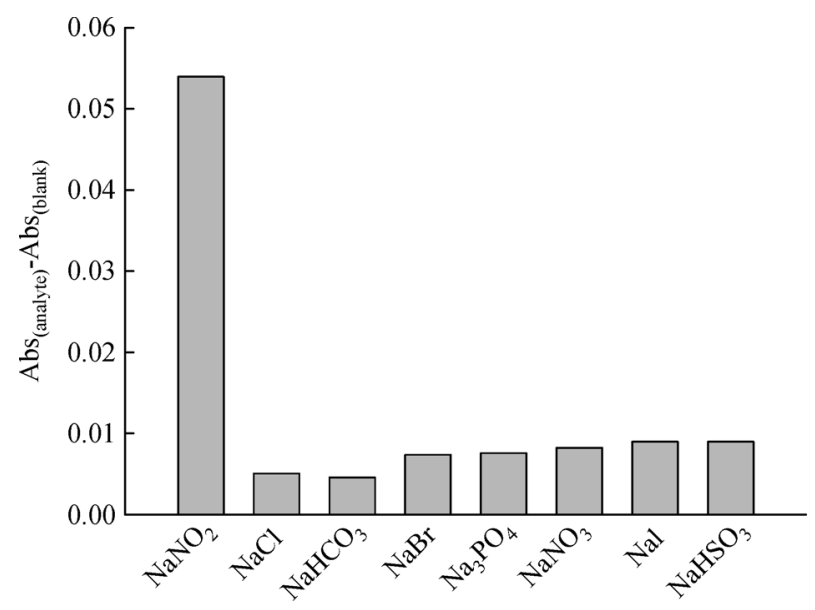

Fig. 6 Selectivity of azulene probe 9 and various anions in solution after $20 \mathrm{~min}$, measuring $\lambda_{\max } 395 \mathrm{~nm}$. Each sample was tested in a mixture of $\mathrm{MeCN}(4.95 \mathrm{~mL})$, DI water $(1.95 \mathrm{~mL})$, $\mathrm{HCl}_{(\mathrm{aq})} 35 \%(3.00 \mathrm{~mL})$, sensor $(50 \mu \mathrm{L}, 5 \mathrm{mmol} / \mathrm{L}$ in $\mathrm{MeCN})$ and analyte $(50 \mu \mathrm{L}, 5 \mathrm{mmol} / \mathrm{L}$ in DI water)

The detection limit of sensor 9 was also determined. For instrumental (spectrophotometric) detection, the limit of detection was determined to be $0.23 \mathrm{mg} / \mathrm{L}$ nitrite. A nakedeye detection limit experiment was also performed (see ESM for details), and sensor 9 was found to show a clear visible response to nitrite at concentrations of $\geqslant 50 \mathrm{mg} / \mathrm{L}$. In addition, kinetic studies were undertaken (see ESM for details) which indicated a relationship between analyte concentration and rate of color change.

To assess the feasibility of using sensor 9 in a practical scenario, the nitrite content of a sample of cured meat was assessed. Sodium nitrite was extracted from commercially available pepperoni using the methodology described by the British Standards 'Method of test for meat and meat products - Determination of nitrite content' (BS 4401-8) [51]. Assaying the extract with azulene probe 9, it was determined that the nitrite concentration in the pepperoni tested was $10.3 \mathrm{mg} / \mathrm{kg}$ (see ESM for details). For comparison, using the Griess methodology described by the British Standards procedure, a nitrite concentration of $10.8 \mathrm{mg} / \mathrm{kg}$ was determined.

\section{Conclusions}

Azulene probe 9 was synthesised over three steps with an overall yield of $72 \%$. The compound was shown to change color rapidly in the presence of nitrite under acidic conditions, forming diazoquinone 12. This process was shown to be highly selective for nitrite over other common anionic analytes, allowing 9 to act as a selective, 1:1 colorimetric chemodosimeter for nitrite. The applicability of the sensor was demonstrated by testing nitrite content in cured meat, for which a result was obtained that was comparable to that acquired using the current British Standard of testing. Advantages of our method include the rapidity of the initial color change (formation of the diazonium intermediate) and the requirement to prepare only a single stock solution of the reagent, as opposed to the multiple stock solutions required for the Griess reagents.

\begin{abstract}
Acknowledgements We are grateful for Ph.D. funding to C.M.L.-A. from the EU Horizon 2020 research and innovation programme under grant agreement H2020-MSCA-CO-FUND, \#665992. The Centre for Sustainable Chemical Technologies is supported by EPSRC under grant EP/L016354/1. We also thank EPSRC for DTP Ph.D. funding to L.C.M. T.D.J. wishes to thank the Royal Society for a Wolfson Research Merit Award. NMR and MS facilities were provided through the Material and Chemical Characterisation Facility (MC2) at the University of Bath.
\end{abstract}

Electronic Supplementary Material Supplementary material is available in the online version of this article at https://doi.org/10.1007/s11705-0191790-7 and is accessible for authorized users.

Open Access This article is licensed under a Creative Commons Attribution 4.0 International License, which permits use, sharing, adaptation, distribution and reproduction in any medium or format, as long as you give appropriate credit to the original author(s) and the source, provide a link to the Creative Commons licence, and indicate if changes were made. The images or other third party material in this article are included in the article's Creative Commons licence, unless indicated otherwise in a credit line to the material. If material is not included in the article's Creative Commons licence and your intended use is not permitted by statutory regulation or exceeds the permitted use, you will need to obtain permission directly from the copyright holder. To view a copy of this licence, visit http://creativecommons.org/licenses/by/4.0/.

\section{References}

1. Safa H, Portanguen S, Mirade P S. Reducing the levels of sodium, saturated animal fat, and nitrite in dry-cured pork meat products: A major challenge. Food and Nutrition Sciences, 2017, 8(4): 419-443

2. Leistner L. Properties of Water in Foods in Relation to Quality and Stability. Dordrecht: Martinus Nijhoff, 1985, 309-329

3. Agudo A, Cantor K P, Chan P C, Chorus I, Falconer I R, Fan A, Fujiki H, Karagas M, Lankoff A, Levallois $P$, et al. IARC Monographs on the Evaluation of Carcinogenic Risks to Humans Volume 94 Ingested Nitrate and Nitrite, and Cyanobacterial Peptide Toxins. Lyon: International Agency for Research on Cancer, 2010, 43-326

4. Hambridge T. Safety Evaluation of Food Additives-WHO Food Additives Series Number 50_JECFA Monograph Number 1059. Geneva: World Health Organisation, 2003, 1-100

5. National Primary Drinking Water Regulations. Washington: United States Environmental Protection Agency, 2009, 1-7 
6. World Health Organization. Guidelines for Drinking-Water Quality, 4th Edition, Incorporating the 1st Addendum. Geneva: World Health Organization, 2017, 155-201

7. Commission Directive (EU)2015/1787 of 6 October 2015 Amending Annexes II and III to Council Directive 98/83/EC on the Quality of Water Intended for Human Consumption. Brussels: European Commission, 2015, 1-12

8. Griess J P. Remarks on the treatise of Weselsky and Benedict on some azo compounds. Berichte der Deutschen Chemischen Gesellschaft, 1879, 12(1): 426-428 (in German)

9. Fox J B Jr. Kinetics and mechanisms of the Griess reaction. Analytical Chemistry, 1979, 51(9): 1493-1502

10. Daniel W L, Han M S, Lee J S, Mirkin C A. Colorimetric nitrite and nitrate detection with gold nanoparticle probes and kinetic end points. Journal of the American Chemical Society, 2009, 131(18): 6362-6363

11. Xiao N, Yu C. Rapid-response and highly sensitive noncross-linking colorimetric nitrite sensor using 4-aminothiophenol modified gold nanorods. Analytical Chemistry, 2010, 82(9): 3659-3663

12. Zhang J, Yang C, Wang X, Yang X. Colorimetric recognition and sensing of nitrite with unmodified gold nanoparticles based on a specific diazo reaction with phenylenediamine. Analyst (London), 2012, 137(14): 3286-3292

13. Chen Z, Zhang Z, Qu C, Pan D, Chen L. Highly sensitive label-free colorimetric sensing of nitrite based on etching of gold nanorods. Analyst (London), 2012, 137(22): 5197-5200

14. Xiong Y, Li M, Liu H, Xuan Z, Yang J, Liu D. Janus PEGylated gold nanoparticles: A robust colorimetric probe for sensing nitrite ions in complex samples. Nanoscale, 2017, 9(5): 1811-1815

15. Kumar V V, Anthony S P. Highly selective silver nanoparticles based label free colorimetric sensor for nitrite anions. Analytica Chimica Acta, 2014, 842: 57-62

16. Centelles J J, Fernández-Cancio M, Imperial S. Spectrophotometric determination of nitrites in biological samples using 1,2-diaminoanthraquinone-potential application to the determination of nitric oxide synthase activity. Analytical Letters, 2003, 36(10): 21392149

17. Dey R, Chatterjee T, Ranu B C. Facile cyclization of 2-arylethynylaniline to $4(1 \mathrm{H})$-cinnolones: A new chemodosimeter for nitrite ions. Tetrahedron Letters, 2011, 52(3): 461-464

18. Dey R, Ranu B C. A convenient and efficient protocol for the synthesis of 4(1H)-cinnolones, 1,4-dihydrocinnolines, and cinnolines in aqueous medium: Application for detection of nitrite ions. Tetrahedron, 2011, 67(46): 8918-8924

19. Adarsh N, Shanmugasundaram M, Ramaiah D. Efficient reaction based colorimetric probe for sensitive detection, quantification, and on-site analysis of nitrite ions in natural water resources. Analytical Chemistry, 2013, 85(21): 10008-10012

20. Zhu J, Li C, Liu S, Liu Z, Yang J, Tian J, Hu X. A non-diazotizationcoupling reaction-based colorimetric determination of nitrite in tap water and milk. European Food Research and Technology, 2014, 238(5): 889-894

21. Sawicki E, Stanley T W, Pfaff J, Johnson H. Sensitive new methods for autocatalytic spectrophotometric determination of nitrite through free-radical chromogens. Analytical Chemistry, 1963, 35(13): 2183-2191
22. Shu Q, Bats J W, Schmittel M. Two closely related iridium(III) complexes as colorimetric and fluorometric chemodosimeters for nitrite in aqueous solution operating along different modes of action. Inorganic Chemistry, 2011, 50(21): 10531-10533

23. Yang S, Wo Y, Meyerhoff M E. Polymeric optical sensors for selective and sensitive nitrite detection using cobalt(III) corrole and rhodium(III) porphyrin as ionophores. Analytica Chimica Acta, 2014, 843: 89-96

24. Liu R S H. Colorful azulene and its equally colorful derivatives. Journal of Chemical Education, 2002, 79(2): 183-185

25. Liu R S H, Asato A E. Tuning the color and excited state properties of the azulenic chromophore: NIR absorbing pigments and materials. Journal of Photochemistry and Photobiology A Chemistry, 2003, 4(3): 179-194

26. Ghazvini Zadeh E H, Tang S, Woodward A W, Liu T, Bondar M V, Belfield K D. Chromophoric materials derived from a natural azulene: Syntheses, halochromism and one-photon and two-photon microlithography. Journal of Materials Chemistry. C, Materials for Optical and Electronic Devices, 2015, 3(33): 8495-8503

27. Lichosyt D, Wasiłek S, Dydio P, Jurczak J. The influence of binding site geometry on anion-binding selectivity: A case study of macrocyclic receptors built on the azulene skeleton. Chemistry (Weinheim an der Bergstrasse, Germany), 2018, 24(45): 1168311692

28. Buica G O, Lazar I G, Birzan L, Lete C, Prodana M, Enachescu M, Tecuceanu V, Stoian A B, Ungureanu E M. Azulene-ethylenediaminetetraacetic acid: A versatile molecule for colorimetric and electrochemical sensors for metal ions. Electrochimica Acta, 2018, 263: 382-3902

29. López-Alled C M, Sanchez-Fernandez A, Edler K J, Sedgwick A C, Bull S D, McMullin C L, Kociok-Köhn G, James T D, Wenk J, Lewis S E. Azulene-boronate esters: Colorimetric indicators for fluoride in drinking water. Chemical Communications, 2017, 53 (93): 12580-12583

30. Wakabayashi S, Uchida M, Tanaka R, Habata Y, Shimizu M. Synthesis of azulene derivatives that have an azathiacrown ether moiety and their selective color reaction towards silver ions. Asian Journal of Organic Chemistry, 2013, 2(9): 786-791

31. Tang T, Lin T, Erden F, Wang F K, He C. Configuration-dependent optical properties and acid susceptibility of azulene compounds. Journal of Materials Chemistry. C, Materials for Optical and Electronic Devices, 2018, 6(19): 5153-5160

32. Lichosyt D, Dydio P, Jurczak J. Azulene-based macrocyclic receptors for recognition and sensing of phosphate anions. Chemistry (Weinheim an der Bergstrasse, Germany), 2016, 22 (49): 17673-17680

33. Gai L, Chen J, Zhao Y, Mack J, Lu H, Shen Z. Synthesis and properties of azulene-functionalized BODIPYs. RSC Advances, 2016, 6(38): 32124-32129

34. Zieliński T, Kędziorek M, Jurczak J. The azulene moiety as a chromogenic building block for anion receptors. Tetrahedron Letters, 2005, 46(37): 6231-6234

35. Cowper P, Pockett A, Kociok-Köhn G, Cameron P J, Lewis S E. Azulene-thiophene-cyanoacrylic acid dyes with donor- $\pi$-acceptor structures: Synthesis, characterisation and evaluation in dyesensitized solar cells. Tetrahedron, 2018, 74(22): 2775-2786 
36. Gee A P, Cosham S D, Johnson A L, Lewis S E. Phosphorussubstituted azulenes accessed via direct Hafner reaction of a phosphino cyclopentadienide. Synlett, 2017: 973-975

37. Cowper P, Jin Y, Turton M D, Kociok-Köhn G, Lewis S E. Azulenesulfonium salts: Accessible, stable, and versatile reagents for cross-coupling. Angewandte Chemie International Edition, 2016, 55(7): 2564-2568

38. Wu D, Sedgwick A C, Gunnlaugsson T, Akkaya E U, Yoon J, James $\mathrm{T}$ D. Fluorescent chemosensors: The past, present and future. Chemical Society Reviews, 2017, 46(23): 7105-7123

39. Sawicki E, Stanley T W, Pfaff J, D’Amico A. Comparison of fiftytwo spectrophotometric methods for the determination of nitrite. Talanta, 1963, 10(6): 641-655

40. Garcia E E. Determination of nitrite ion using the reaction with $p$-nitroaniline and azulene. Analytical Chemistry, 1967, 39(13): $1605-1607$

41. Fang H, Gan Y, Wang S, Tao T. A selective and colorimetric chemosensor for fluoride based on dimeric azulene boronate ester. Inorganic Chemistry Communications, 2018, 95: 17-21

42. Nefedov V A, German N A, Nikishin G I. Anomalous orientation in the nitration of azulene by copper(II) nitrite in pyridine: Preparation of 2-nitroazulene. Zhurnal Organicheskoi Khimii, 1983, 9: 1123 1124

43. Anderson A G Jr, Haddock R D. The reaction of azulene and azupyrene with silver nitrite and of azupyrene with nitrogen dioxide/ dinitrogen tetroxide. New Journal of Chemistry, 1992, 16: 919-922

44. Nozoe T, Seto S, Matsumura S. Synthesis of 2-substituted azulenes by nucleophilic substitution reactions of 2-haloazulene derivatives. Bulletin of the Chemical Society of Japan, 1962, 35(12): 1990-1998

45. Nozoe T, Takase K, Kato M, Nogi T. Reaction of 2-arylsulfonyloxytropones and active methylene compounds: Formation of 8hydroxy-2H-cyclohepta[b]furan-2-one and 2-amino- 8 H-cyclohepta [b]furan-8-one derivatives. Tetrahedron, 1971, 27(24): 6023-6035

46. Wang Y W, Hua Y X, Wu H H, Sun X, Peng Y. A solvent-tuning fluorescence sensor for $\mathrm{In}(\mathrm{III})$ and $\mathrm{Al}(\mathrm{III})$ ions and its bioimaging application. Chinese Chemical Letters, 2017, 28(10): 1994-1996

47. Wang Y W, Liu S B, Ling W J, Peng Y. A fluorescent probe for relay recognition of homocysteine and Group IIIA ions including $\mathrm{Ga}$ (III). Chemical Communications, 2016, 52(4): 827-830

48. Ma T H, Dong M, Dong Y M, Wang Y W, Peng Y. A unique watertuning dual-channel fluorescence-enhanced sensor for aluminum ions based on a hybrid ligand from a 1,1'-binaphthyl scaffold and an amino acid. Chemistry (Weinheim an der Bergstrasse, Germany), 2010, 16(34): 10313-10318

49. Nozoe T, Asao T, Susumago H, Ando M. The diazotization of 2aminoazulene derivatives: The formation of 2-diazo-2,6-azulenoquinone derivatives. Bulletin of the Chemical Society of Japan, 1974, 47(6): 1471-1476

50. Romański J, Piątek P. Selective ammonium nitrate recognition by a heteroditopic macrotricyclic ion-pair receptor. Journal of Organic Chemistry, 2013, 78(9): 4341-4347

51. Methods of Test for Meat and Meat Products. Part 8. Determination of Nitrite Content; BS 4401-8: 1976. London: British Standards Institute, 2011, 1-10 